\title{
CHARACTERIZATION OF MACROPHAGES AND NEUTROPHILIC GRANULOCYTES FROM THE PRONEPHROS OF CARP (CYPRINUS CARPIO)
}

\author{
B. M. LIDY VERBURG-VAN KEMENADE, ADRIE GROENEVELD, \\ BIRGITTE T. T. M. VAN RENS AND JAN H. W. M. ROMBOUT \\ Department of Experimental Animal Morphology and Cell Biology, Agricultural \\ University, PO Box 338, 6700AH Wageningen, The Netherlands
}

Accepted 27 September 1993

\begin{abstract}
Summary
To analyse the functional activity of different leucocyte types, carp pronephros cells were separated on Percoll density gradients and by use of fluorescence-activated cell sorting. Cell populations were characterised by light and electron microscopy and by flow cytometry. Fractions enriched in macrophages and neutrophilic granulocytes were subsequently analysed for phagocytic activity in vitro by quantification of the uptake of Escherichia coli bacteria or yeast cells, and for respiratory burst response by measurement of the production of the reactive oxygen intermediates $\mathrm{O}_{2}{ }^{*}$ and $\mathrm{H}_{2} \mathrm{O}_{2}$. Both cell types showed very active in vitro phagocytosis and production of both $\mathrm{O}_{2}{ }^{*}$ and $\mathrm{H}_{2} \mathrm{O}_{2}$. When activated with phorbol myristate acetate or bacteria, it was evident that the neutrophilic granulocytes were significantly more active than the macrophages.

Analysis of single-cell respiratory burst activity in fish phagocytes was investigated after preloading of cells with dihydrorhodamine123. Cells were subsequently separated and analysed for fluorescence using flow cytometry. Both the macrophage-enriched fraction and the granulocyte-enriched fraction appeared to consist of active and inactive subpopulations. In comparison with the inactive populations, active populations had characteristic high forward/sideward scatter profiles.
\end{abstract}

\section{Introduction}

It is now widely accepted that teleostean fish have leucocyte subpopulations consisting of lymphocytes, monocytes, macrophages, granulocytes and non-specific cytototoxic cells. However, their identification, functions and relative contributions to specific and non-specific immune responses are still a matter of debate (Rowley et al. 1988; Hine, 1992). In fish, phagocytosis has been recognised as an important element in the host's defence against invading microorganisms (MacArthur and Fletcher, 1985; Olivier et al. 1986). There is growing evidence that, as in mammals, macrophages play an important role in the regulation of the humoral response by secreting cytokines (Cohen and Haynes,

Key words: macrophages, neutrophilic granulocytes, phagocytosis, respiratory burst, oxygen radicals, flow cytometry, di-hydrorhodamine123, carp, Cyprinus carpio. 
1991; Secombes, 1991; Verburg-van Kemenade et al. 1991). The activation of phagocytic, microbiocidal and secretory activity of fish macrophages also seems to be selectively regulated, not only by microorganisms or their products, but also by neuroendocrine messages (Blalock, 1992; Bayne and Levy, 1991). A detailed study of the activity and activation of macrophages and neutrophilic granulocytes will give insight into the function of these cells in the immune responses of fish. The generation of oxygen metabolites for effecting microbiocidal activity has been established in teleosts (Chung and Secombes, 1987, 1988). Both the generation of superoxide anions through reduction of oxygen by $\mathrm{NAD}(\mathrm{P}) \mathrm{H}$ and the superoxide-dismutase-catalysed generation of $\mathrm{H}_{2} \mathrm{O}_{2}$ have been demonstrated for trout macrophages (Secombes et al. 1988).

No carp leucocyte cell lines are available, so experiments have been performed with cells isolated from the pronephros, a major haematopoietic tissue in fish (Bielek, 1981; Ellis, 1977).

We have isolated five fractions of pronephric cells on the basis of differences in cell density. Fractions were characterised by light and electron microscopy (EM). As separation of cells by density gradients does not yield homogeneous fractions, a further separation based on cell size, and on membrane and cytoplasmic structure, was carried out using flow cytometry. Different cell populations within the fractions were characterised by combined fluorescence-activated cell sorting and EM analysis. In addition, we measured the in vitro phagocytic activity. Activation of respiratory burst was measured with the Nitro Blue Tetrazolium (NBT) reduction assay for quantification of intracellular $\mathrm{O}_{2} *$ and by measurement of Phenol Red oxidation for determination of extracellularly generated $\mathrm{H}_{2} \mathrm{O}_{2}$.

More precise flow cytometric tests have recently become available to determine the reactive oxygen intermediate (ROI) production at the single-cell level. One of these involves uptake by phagocytes of the non-fluorescent dye dihydrorhodamine 123 (DHR123), which is retained within the cells at mitochondrial binding sites. Fluorescence emission can be measured after ROI-induced oxidation to rhodamine123 (Rothe et al. 1988). Application of this technique to fish phagocytes allowed us to determine respiratory burst activity in subpopulations of the cell fractions.

\section{Materials and methods}

\section{Animals}

Common carp, Cyprinus carpio L., provided by 'De Haar vissen', were reared at $23{ }^{\circ} \mathrm{C}$ in recirculating, ultraviolet-sterilized water and fed daily with dry food pellets (K30 Trouw, Putten, The Netherlands). We used animals aged 8-18 months, weighing approximately $200 \mathrm{~g}$. They were anaesthetised in tricaine methane sulphonate (Crescent Research Chemicals, Phoenix, USA) and blood was collected from the caudal vein before dissection of the pronephros tissue.

\section{Isolation of cells}

Only siliconized (Sigmacoat, Sigma, Belgium) glass or plastic material was used in the isolation procedure. Pronephros cell suspensions were prepared by mincing the 
pronephros tissue through a $50 \mu \mathrm{m}$ mesh nylon gauze filter in an adjusted RPMI 1640 medium $(270$ mosmol kg-1). Cells were separated on a Percoll (Pharmacia, Sweden) $60 \%$ continuous density gradient with an apparent density range of $1.015-1.145 \mathrm{~g} \mathrm{~cm}^{-3}$ or on a discontinuous density gradient of $1.02-1.06,1.06-1.07$ and $1.07-1.083 \mathrm{~g} \mathrm{~cm}^{-3}$. The cells were washed three times and resuspended to a density of $10^{7}$ cells $\mathrm{ml}^{-1}$. For measurement of NBT reduction or Phenol Red oxidation, cells were allowed to adhere to the surface of microtitre plates $\left(100 \mu \mathrm{l}\right.$ per well). After $1 \mathrm{~h}$ at $26^{\circ} \mathrm{C}$, under $5 \% \mathrm{CO}_{2}$, the supernatant with non-adherent cells was removed, and the remaining cells were washed three times in adjusted RPMI medium.

\section{Electron microscopy}

Cell fractions were washed three times and the pellets were fixed in $1 \%(\mathrm{w} / \mathrm{v})$ $\mathrm{K}_{2} \mathrm{Cr}_{2} \mathrm{O}_{7}, 2 \%$ (v/v) glutaraldehyde and $1 \% \mathrm{OsO}_{4}$ in $0.1 \mathrm{moll}^{-1}$ sodium cacodylate buffer, $\mathrm{pH} 7.2$, for $1 \mathrm{~h}$ at $0^{\circ} \mathrm{C}$. They were then washed in double-distilled water, dehydrated with graded ethanols and propylene oxide and embedded in Epon 812. Ultrathin sections were cut on a Reichert Ultracut E ultramicrotome. After staining with uranyl acetate and lead citrate, sections were examined with a Philips 201 EM.

\section{Flow cytometry}

Cell fractions were analysed in RPMI (adjusted to 270 mosmol $\mathrm{kg}^{-1}$ ) for forward (FSC) and sideward (SSC) scatter patterns in a fluorescence-activated cell sorter (FACStar, Becton and Dickenson, Belgium). Gates were defined to identify populations of cells with different FSC/SSC characteristics. Sorting of cell populations was performed on cell suspensions $\left(10^{7}\right.$ cells ml $\left.{ }^{-1}\right)$ at a rate of $10^{6} \mathrm{cells}^{-1}$. The sorted populations were washed twice and subsequently prepared for EM analysis.

In vitro phagocytosis

Phagocytosis was performed in vitro at a concentration of $10^{7}$ leucocytes $\mathrm{ml}^{-1}$ with a 10-fold excess over leucocytes of Escherichia coli (E7) or a 50-fold excess over leucocytes of yeast cells, stained for $3 \mathrm{~min}$ at $90{ }^{\circ} \mathrm{C}$ with Congo Red. Opsonisation of bacteria or yeast cells was performed in $50 \%$ pooled carp serum for $30 \mathrm{~min}$ at $26^{\circ} \mathrm{C}$. Phagocytosis was quantified after $1 \mathrm{~h}$ by counting (using the EM) the number of ingested bacteria visible in 100 ultrathin sectioned cells of one type or by counting the number of ingested cells visible in 100 cells of a particular type, visualized by light microscopy.

\section{Respiratory burst activity}

Detection of intracellular superoxide anions by NBT is based on the methods of Pick and Mizel (1981) and Rook et al. (1985). Quadruplicate monolayers of $10^{6}$ adherent cells per well were prepared. After $1 \mathrm{~h}$, non-adhering cells were removed by rinsing twice in RPMI without Phenol Red. The average percentage of adhering cells of both fractions was determined by lysing the cells with $0.1 \mathrm{moll}^{-1}$ citric acid, $1 \%$ Tween (Merck, BRD), $0.5 \%$ Crystal Violet (Merck, BRD), and counting the nuclei in a haemocytometer. After 
addition of $150 \mu \mathrm{l}$ of NBT solution ( $1 \mathrm{mg} \mathrm{ml}^{-1}$ in RPMI) (Sigma, USA), the monolayers were incubated with or without stimuli for $90 \mathrm{~min}$ at $26^{\circ} \mathrm{C}$, under $5 \% \mathrm{CO}_{2}$. The medium was subsequently removed, the monolayer was rinsed and the cells were fixed in $100 \%$ methanol. Cells were washed three times in $70 \%$ methanol and air-dried. The formazan in each well was dissolved in $120 \mu \mathrm{l}$ of $2 \mathrm{moll}^{-1} \mathrm{KOH}$ and $140 \mu \mathrm{l}$ of dimethylsulphoxide (DMSO) by mixing, and the optical density was read in a multiscan reader (Anthos 2001/1) at $690 \mathrm{~nm}$ with reference to $430 \mathrm{~nm}$ against a blank without cells.

Detection of extracellular $\mathrm{H}_{2} \mathrm{O}_{2}$ with Phenol Red was based on the methods of Pick and Keisari (1980) and Pick and Mizel (1981). The monolayers of adhering cells were rinsed three times in Hanks balanced salt solution (HBSS) without Phenol Red (Gibco, The Netherlands) at a pH of 7.2. Next, cells were incubated with or without stimuli at $26^{\circ} \mathrm{C}$, under $5 \% \mathrm{CO}_{2}$, for $30 \mathrm{~min}$ in $100 \mu \mathrm{l}$ of $0.2 \mathrm{~g} \mathrm{l}^{-1}$ Phenol Red solution in HBSS to which 20 i.u. of horseradish peroxidase (HRP, type VI, 200 i.u. $\mathrm{mg}^{-1}$, Sigma, USA) had been added immediately before use. The reaction was stopped by the addition of $10 \mu \mathrm{l}$ of $1 \mathrm{moll}^{-1} \mathrm{NaOH}$ solution to each well. The plates were shaken for $10 \mathrm{~s}$ and the optical density was immediately determined at $600 \mathrm{~nm}$ in a multiscan reader.

\section{Flow cytometry analysis of respiratory burst activity}

The following is based on the method of Emmendorfer et al. (1990). Cells $\left(3 \times 10^{6} \mathrm{ml}^{-1}\right)$ from Percoll fractions $1+2$ and fraction 3 were incubated for $1 \mathrm{~h}$ with or without 0.01 or $0.05 \mu \mathrm{g} \mathrm{ml}^{-1}$ phorbol myristate acetate (PMA) (Sigma, USA) in siliconized tubes at $26^{\circ} \mathrm{C}$ under $5 \% \quad \mathrm{CO}_{2}$. Subsequently, $2 \mu \mathrm{g} \mathrm{ml}^{-1}$ dihydrorhodamine123 (DHR123, Molecular Probes Inc, USA) in $N, N$ dimethylformamide was added and cells were incubated for another $60 \mathrm{~min}$. At time zero and after every incubation step, 10000 cells were analysed with the flow cytometer for FSC and SSC patterns and for changes in fluorescence (FL1).

\section{Results}

\section{Characteristics of the pronephros cell suspensions}

Five leucocyte fractions of different density ranges were obtained by either continuous or discontinuous Percoll gradient centrifugation. In addition, fraction 5 could be further subdivided into two sharp bands ( $5 \mathrm{a}$ and $5 \mathrm{~b}$ ) in a continuous gradient. The cell viability was consistently greater than $95 \%$. Throughout the isolation procedure, the fractions were analysed by EM to assess their ultrastructural features. Fraction 1 consisted mainly of lymphocytes (40-50\%) and (predominantly) small macrophages (30-40\%). A few neutrophilic (10-15\%) and some basophilic granulocytes (fewer than $5 \%$ ) were detected in this fraction. Fraction 2 contained an abundance of macrophages (30-40\%), both small (approximately $4 \mu \mathrm{m}$ ) and larger (approximately $8 \mu \mathrm{m}$ ) ones; approximately $30 \%$ lymphocytes and $30 \%$ neutrophilic granulocytes. In fraction 3 , the main population consisted of neutrophilic granulocytes $(80 \%)$. The remaining $20 \%$ consisted of basophilic granulocytes, macrophages and lymphocytes. Fraction 4 consisted of erythrocytes, which were also found occasionally in fractions 3 and 5. Fraction 5 
contained basophilic (50\%), eosinophilic $(15 \%)$ and intermediate $(20 \%)$ granulocytes and a population of mainly large macrophages $(15 \%)$.

In all fractions, macrophages were identified as monocyte-like cells by their size and by their relatively small number of lysosomes. No large melanomacrophages could be detected in the suspensions. Neither macrophages nor granulocytes obtained from different fractions showed significant ultrastructural differences.

EM analysis only allows an estimation of the percentage of different cell types, so the fractions were also quantified by counting the cells under the light microscope (Table 1). This analysis gave values for fractions of small cells (consisting of lymphocytes and small macrophages), for macrophages and for granulocytes. It was not possible to distinguish between lymphocytes and small macrophages, and between the different types of granulocytes, with this technique.

A well-known characteristic of macrophages and granulocytes is their capacity to adhere to glass or plastic. Therefore, the percentage of adhering cells was determined (Table 1). Macrophages started to spread over the surface within the first minutes of culture, whereas neutrophilic granulocytes adhered, but remained globular after several hours in culture.

Flow cytometric analyses of FSC/SSC profiles of the pronephric cells, and those of Percoll fractions of pronephric cell suspensions, yielded two main populations for which the typical profiles and gate settings $(A$ and $B$ ) are given in Fig. 1. To characterize the cells within these populations, cell fractions 1,2 and 3 were sorted, and the ultrastructural features of the cells confirmed by electron microscopy. The main cell population in fraction 1 fell in gate $A$, yet this population showed a very heterogeneous FSC pattern, and was therefore divided into two fractions ( $A 1$ and $A 2)$ with, respectively, low and high FSC values (Fig. 1). In gate $A 1$, the cells appeared to be mainly lymphocytes with a smaller number of small macrophages. Gate $A 2$ contained mainly macrophages with some lymphocytes and neutrophilic granulocytes. In fraction 2 , the cell population in gate $A$ consisted of macrophages and lymphocytes, with occasional neutrophilic granulocytes. Gate $B$ consisted of a pure population (more than $95 \%$ ) of neutrophilic granulocytes, with occasional single basophilic granulocytes. In fraction 3 , gate $A$ contained macrophages

Table 1. Characteristics of pronephros leucocyte fractions, isolated on a Percoll density gradient, based on light microscope counts

\begin{tabular}{lcccccc}
\hline & $\begin{array}{c}\text { Cell } \\
\text { density } \\
\left(\mathrm{g} \mathrm{cm}^{-3}\right)\end{array}$ & Cell yield & $\begin{array}{c}\text { Adherence } \\
(\%)\end{array}$ & $\begin{array}{c}\text { Lymphocytes+ } \\
\text { small } \\
\text { Fraction }\end{array}$ & $\begin{array}{c}\text { Granulocytes } \\
(\%)\end{array}$ & $\begin{array}{c}\text { Macrophages } \\
(\%)\end{array}$ \\
\hline 1 & $1.020-1.060$ & $1.5 \times 10^{7} \pm 2.3 \times 10^{7}(8)$ & $35 \pm 12(27)$ & $82 \pm 5(5)$ & $3 \pm 1(5)$ & $15 \pm 1(5)$ \\
2 & $1.060-1.070$ & $2.2 \times 10^{7} \pm 1.8 \times 10^{7}(11)$ & $45 \pm 11(26)$ & $57 \pm 5(5)$ & $10 \pm 5(5)$ & $33 \pm 2(5)$ \\
3 & $1.070-1.083$ & $3.3 \times 10^{7} \pm 2.6 \times 10^{7}(10)$ & $36 \pm 9(20)$ & $26 \pm 6(5)$ & $64 \pm 7(5)$ & $10 \pm 2(5)$ \\
4 & $1.083-1.087$ & $\mathrm{ND}$ & - & $\mathrm{ND}$ & $\mathrm{ND}$ & $\mathrm{ND}$ \\
5 & $1.087-1.093$ & $1.8 \times 10^{6} \pm 1.4 \times 10^{6}(5)$ & $\mathrm{ND}$ & 0 & $85 \pm 7(5)$ & $15 \pm 5(5)$ \\
Total & $1.0 \times 10^{8} \pm 1.2 \times 10^{7}(48)$ & $\mathrm{ND}$ & $62 \pm 4(5)$ & $20 \pm 3(5)$ & $18 \pm 4(5)$ \\
\multicolumn{7}{c}{ Values are means \pm S.D. (number of experiments); ND, not determined. } \\
\hline
\end{tabular}



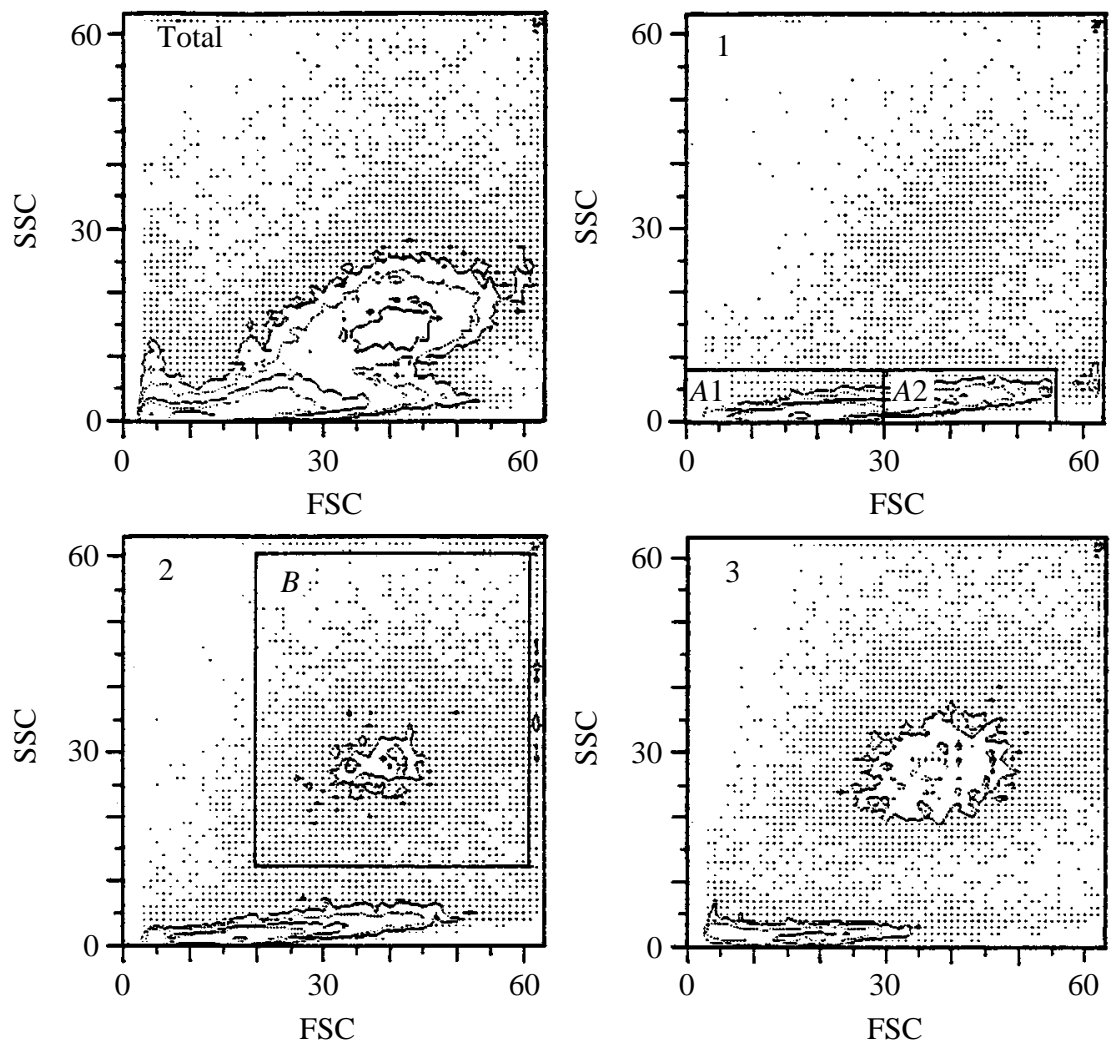

Fig. 1. Forward/sideward scatter (FSC/SSC) dot-plot of a total pronephros cell suspension (Total) and of cells in the Percoll density fractions (1), (2) and (3). The dot-plot for the total cell suspension is given for 50000 cells. Plots for fractions 1, 2 and 3 are given for 18 250, 18670 and 13050 cells, respectively, representing their relative number in the plot of the original suspension. Contour lines are drawn for 10,20,50,100 and 500 cells. The percentage of cells within gates $A$ and $B$ were: for fraction $1,83.3 \%$ (65.9\% in $A 1$ and $16.4 \%$ in $A 2)$ and $8.5 \%$; for fraction $2,63.4 \%$ and $22.8 \%$; and for fraction $3,29.4 \%$ and $50.1 \%$.

and a smaller population of lymphocytes (Fig. 2A). Gate $B$ defined a pure population of neutrophilic granulocytes (Fig. 2B).

\section{Activity of pronephros cells}

\section{Phagocytic activity}

EM analysis of Percoll-separated cells in fractions $1-5$, after $1 \mathrm{~h}$ in vitro incubation with Escherichia coli, revealed active phagocytosis by macrophages and neutrophilic granulocytes. Within $1 \mathrm{~h}$, more than $85 \%$ of all macrophage or neutrophilic granulocyte

Fig. 2. Electron micrographs of cells from Percoll density fraction 3, after sorting by flow cytometry. FSC/SSC patterns and sorting gates are given in Fig. 1. (A) The cell population sorted within gate $A$ consists predominantly of lymphocytes $(l)$ and small macrophages $(m)$. (B) Cell population sorted within gate $B$, neutrophilic $(g)$ granulocytes. Scale bar, $5 \mu \mathrm{m}$. 

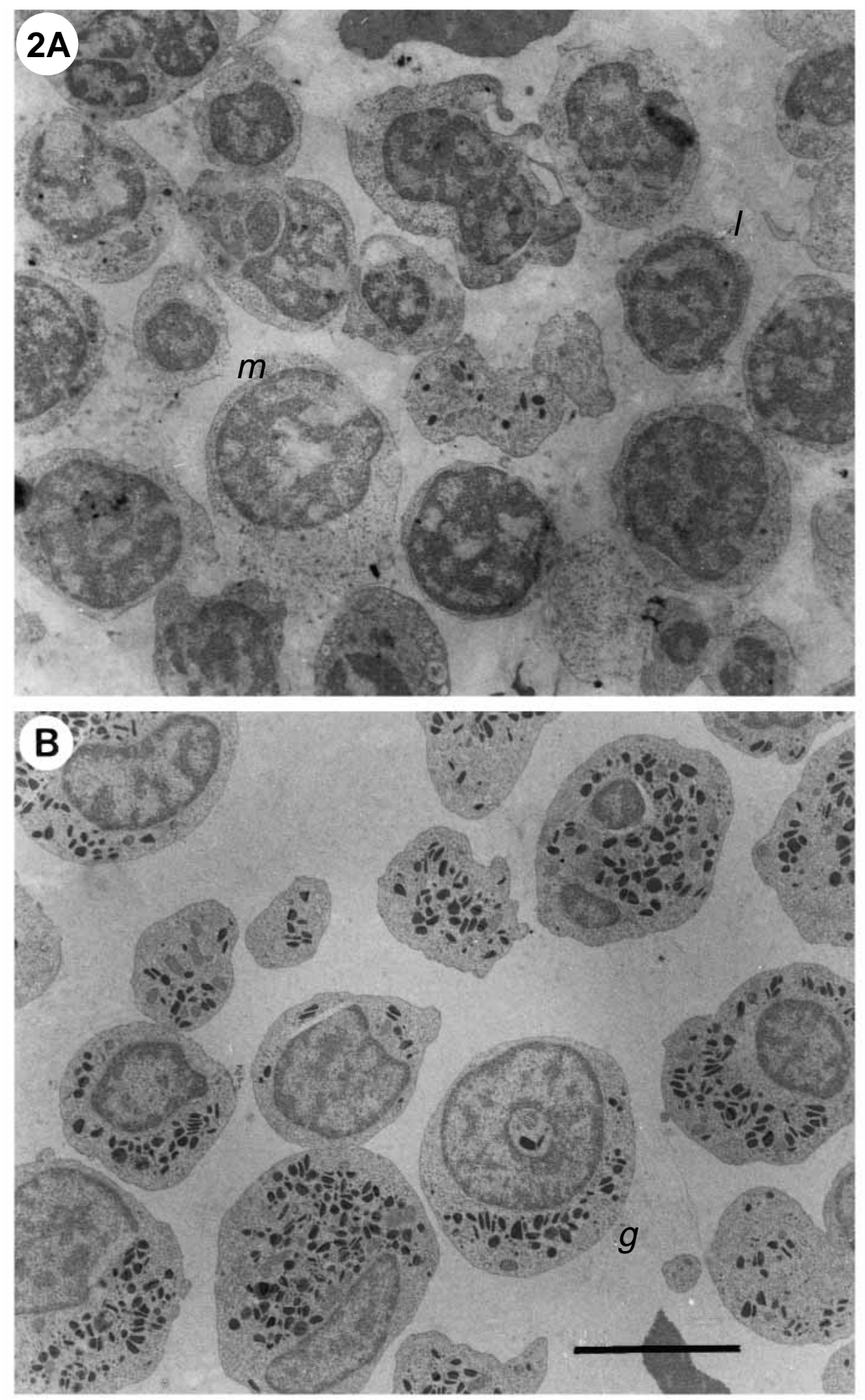

Fig. 2 
Table 2. Phagocytosis of Escherichia coli by pronephros leucocytes

\begin{tabular}{lccc}
\hline Cell type & Percentage & Number & Average \\
\hline Macrophages & $>90$ & $0-50$ & $20-25$ \\
Neutrophilic granulocytes & $>85$ & $0-15$ & $5-8$ \\
Basophilic granulocytes & $<50$ & $0-8$ & $4-5$ \\
Eosinophilic granulocytes & $<40$ & $0-4$ & $1-3$ \\
Intermediate granulocytes & $<50$ & $0-8$ & $4-5$
\end{tabular}

Semi-quantitative electron microscopic analysis of phagocytosis of Eschericia coli bacteria, measured after $1 \mathrm{~h}$ with a 10-fold excess of bacteria over the number of cells, in 100 ultrathin sections of each cell type.

Percentage, the percentage of the sectioned cells containing bacteria; Number, number of bacteria registered per section; Average, average number of bacteria counted per positive section.

The average diameters of nucleus-containing sectioned cells were: $4-8 \mu \mathrm{m}$ for macrophages; $6-7.5 \mu \mathrm{m}$ for neutrophilic granulocytes; $6 \mu \mathrm{m}$ for basophylic, eosinophilic and intermediate granulocytes.

sections contained at least 20 or 5 bacteria, respectively. Basophilic granulocytes, eosinophilic granulocytes and intermediate granulocytes were also phagocytic, yet their activity was considerably lower (Table 2). Phagocytosis of the larger yeast cells was slower than that of bacteria. After $1 \mathrm{~h}, 30 \%$ of the macrophages and neutrophilic granulocytes had phagocytosed, whereas after $2 \mathrm{~h}, 80 \%$ of both cell types had phagocytosed. Opsonisation of bacteria and yeast with non-immune serum increased the in vitro phagocytic activity, both the number of bacteria ingested and the percentage of phagocytic cells, by $40-50 \%$.

\section{Respiratory burst activity}

The NBT reduction assay for adherent cell populations revealed a low basal activity in cells of all three tested fractions (1-3) with, in general, fraction 3 showing the highest activity per cell. Significant stimulation of NBT reduction could be obtained after stimulation by PMA. The time course of NBT reduction after PMA stimulation showed a maximum after $90 \mathrm{~min}$ and plateaued thereafter (Fig. 3A). The cells in fraction 3 appeared to be rapidly stimulated by, and sensitive to, PMA (Fig. 3B); at $0.001 \mu \mathrm{g} \mathrm{ml}^{-1}$ PMA a twofold stimulation was observed. The average maximum stimulation over the basal activity was $371 \%(N=72$, range $155-778 \%)$. This was reached at $0.05 \mu \mathrm{g} \mathrm{ml}^{-1}$. The cells in both fractions 1 and 2 were less sensitive to PMA; $0.01 \mu \mathrm{g} \mathrm{ml}^{-1}$ was effective, with $0.1 \mu \mathrm{g} \mathrm{m}^{-1}$ being maximally effective (Fig. 3B). Average maximal stimulation at $0.1 \mu \mathrm{g} \mathrm{ml}^{-1}$ was $254 \%(N=66$, range $140-478 \%)$ for fractions 1 and 2. Superoxide dismutase (SOD) treatment during the NBT incubation resulted in a $60 \pm 12 \%$ $(N=8)$ decrease of NBT reduction in all fractions. The stimulation of NBT reduction by PMA could also be reduced by $50 \pm 9 \%(N=3)$ (Fig. 3C).

Incubation with PMA can only visualize respiratory burst stimulation through protein kinase activation, so the results were compared with those obtained after incubation with Aeromonas salmonicida (TG36-) bacteria, to represent a natural stimulant of respiratory burst activity. Fig. 4 illustrates the dose-response relationship of induction of NBT reduction by bacteria in fractions $1-3$. Induction of NBT reduction by bacteria was 

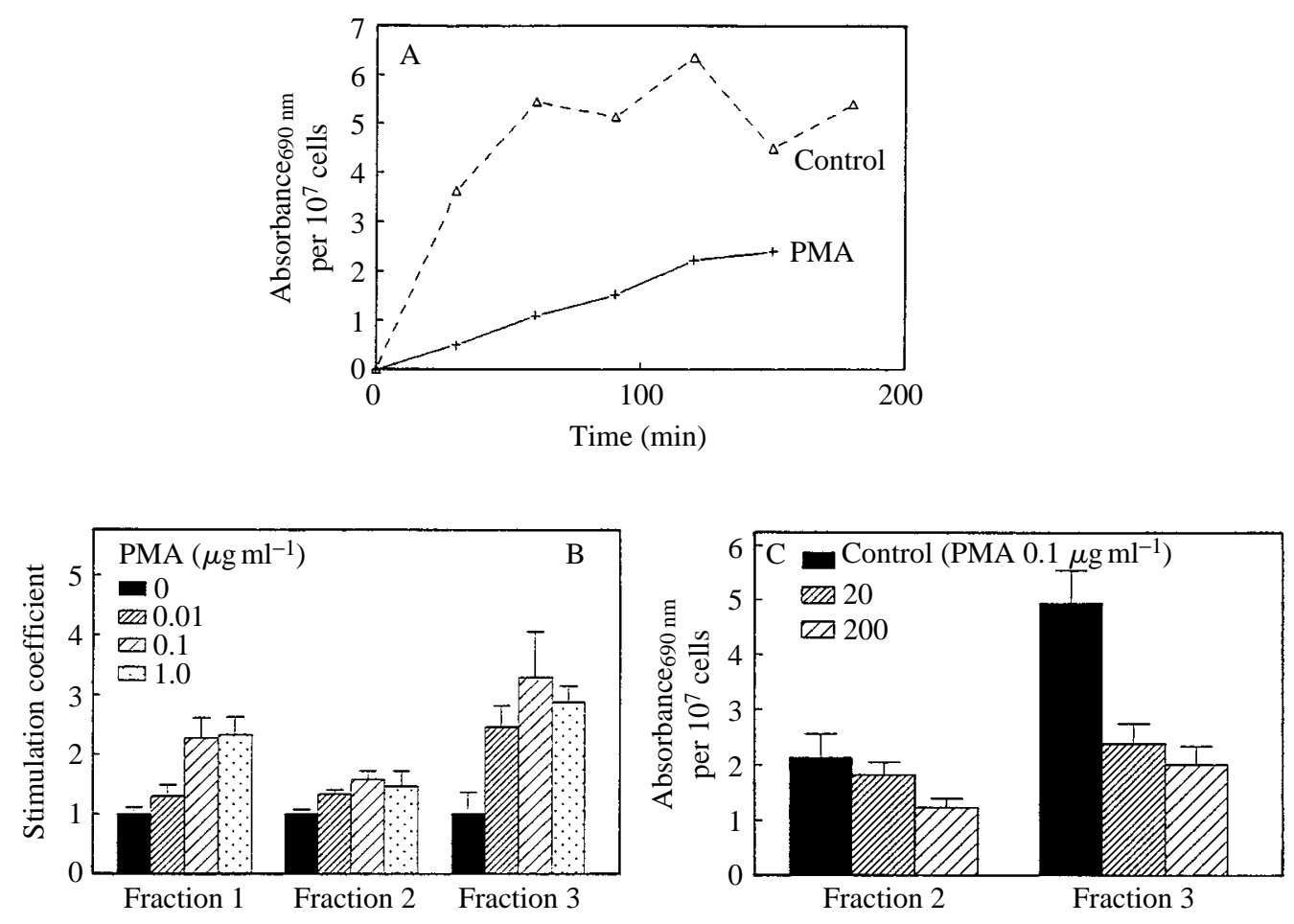

Fig. 3. Determination of intracellular $\mathrm{O}_{2} \dot{*}$ formation in pronephros cell fractions 1,2 and 3 by measurement of Nitro Blue Tetrazolium (NBT) reduction. The values are means \pm S.D. of a quadruplicate experiment. (A) A plot of basal and $0.1 \mu \mathrm{g} \mathrm{ml}^{-1}$ phorbol-myristate-acetateinduced (PMA) reaction in fraction 2 versus time. (B) The dose-response relationship of stimulation by PMA registered after a $90 \mathrm{~min}$ incubation $\left(0.01,0.1\right.$ and $\left.1 \mu \mathrm{g} \mathrm{ml}^{-1}\right)$. For $10^{7}$ cells basic values of absorbance at $690 \mathrm{~nm}$ were: 8 for fraction $1 ; 14$ for fraction $2 ; 12$ for fraction 3. (C) A representative experiment examining the effect of superoxide dismutase (SOD) on PMA-induced $\left(0.1 \mu \mathrm{g} \mathrm{ml}^{-1}\right)$ NBT reduction. SOD concentrations are given in i.u. $\mathrm{ml}^{-1}$. Values are mean \pm S.D., $N=4$.

highest in the cells of fraction 3. Moreover, significantly higher maximum levels of NBT reduction were obtained than those induced by PMA administration (Fig. 4).

Quantification of $\mathrm{H}_{2} \mathrm{O}_{2}$ in the medium of the adherent cells from fractions 1-3, by oxidation of Phenol Red, revealed a similar pattern of activity and activation to that observed in the NBT reduction assays. Maximal responses were obtained within $30 \mathrm{~min}$ (Fig. 5A), and once again fraction 3 generally showed the highest basal activity (Fig. 5B). Fraction 2 cells revealed the highest values after PMA stimulation (Fig. 5B,C). Co-incubation with SOD induced an average increase in Phenol Red oxidation of $28 \pm 6 \%$ $(N=3)$ in fractions 2 and 3 (Fig. 5B,C).

Respiratory burst activity and activation, in both adherent and non-adherent cells, with separate analyses of cell populations within one fraction, were measured by flow cytometry, after loading the cells with dihydrorhodamine123 (DHR123). As shown in Fig. 6, carp leucocytes could be succesfully loaded with DHR123, resulting in a good 


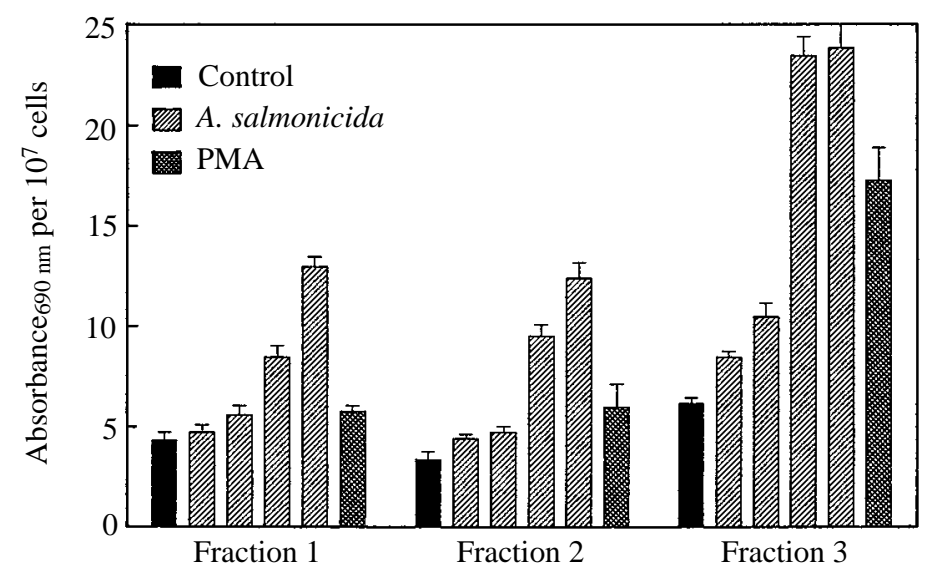

Fig. 4. Comparison of the effects on NBT reduction of an optimal concentration of PMA $\left(0.1 \mu \mathrm{g} \mathrm{ml}^{-1}\right)$ and four different doses of Aeromonas salmonicida (TG36-). Values are means \pm S.D. of a quadruplicate experiment. Concentrations of A. salmonicida were (left to right for each fraction ) $10^{5}, 10^{6}, 10^{7}$ and $10^{8} \mathrm{ml}^{-1}$.
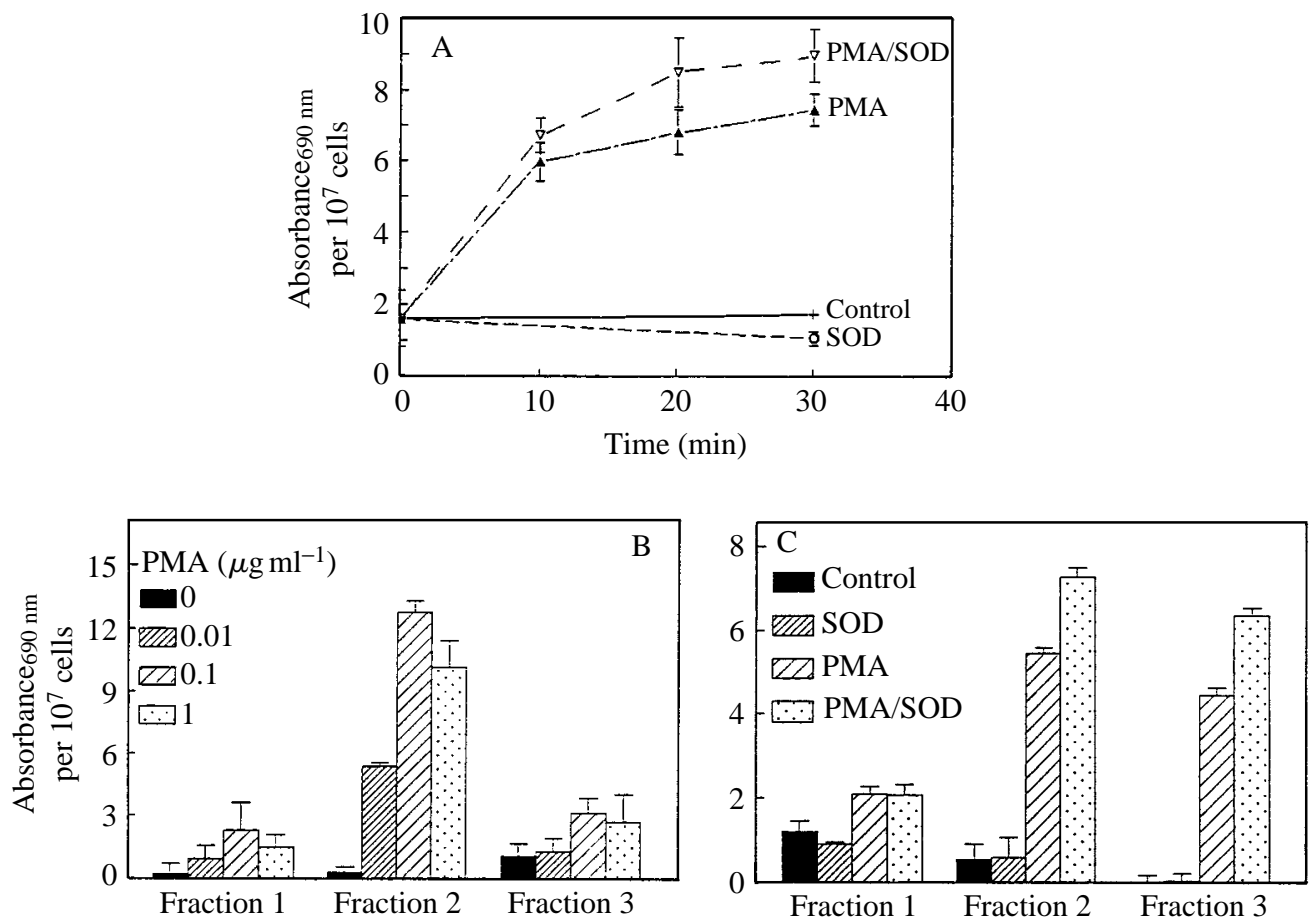

Fig. 5. Determination of $\mathrm{H}_{2} \mathrm{O}_{2}$ formation in pronephros cell fractions 1,2 and 3, by measurement of Phenol Red oxidation. Values are means \pm S.D. of a quadruplicate measurement. (A) Time course of basal and $0.1 \mu \mathrm{g} \mathrm{ml}^{-1}$ PMA-induced reactions in fraction 2, with and without 300 i.u. $\mathrm{ml}^{-1}$ superoxide dismutase. (B) Dose-response relationship for stimulation by PMA $\left(0.01,0.1\right.$ and $\left.1 \mu \mathrm{g} \mathrm{ml}^{-1}\right)$ after a 30 min incubation. (C) Determination of the effect of SOD (300 i.u. $\mathrm{ml}^{-1}$ ) in fractions 1,2 and 3, with and without $0.1 \mu \mathrm{g} \mathrm{ml}^{-1}$ PMA. 
basic fluorescence without generating a shift in FSC/SSC patterns. The FL1 histogram of non-stimulated cells in fraction $1+2$ had two peaks with different intensities of fluorescence. All cells in FSC/SSC gate $B$ had a high basic fluorescence (Fig. 6Aiii), whereas the cell population in gate $A$ predominantly contained cells with a lower fluorescence (Fig. 6Aii). Cells in fraction 3 also revealed these two fluorescence peaks, but in this case most of the cells showed the higher fluorescence value. Again gate $B$ contained a population of cells with a homogeneous and high fluorescence (Fig. 6Biii), whereas gate $A$ contained a cell population with both fluorescence intensities (Fig. 6Bii).
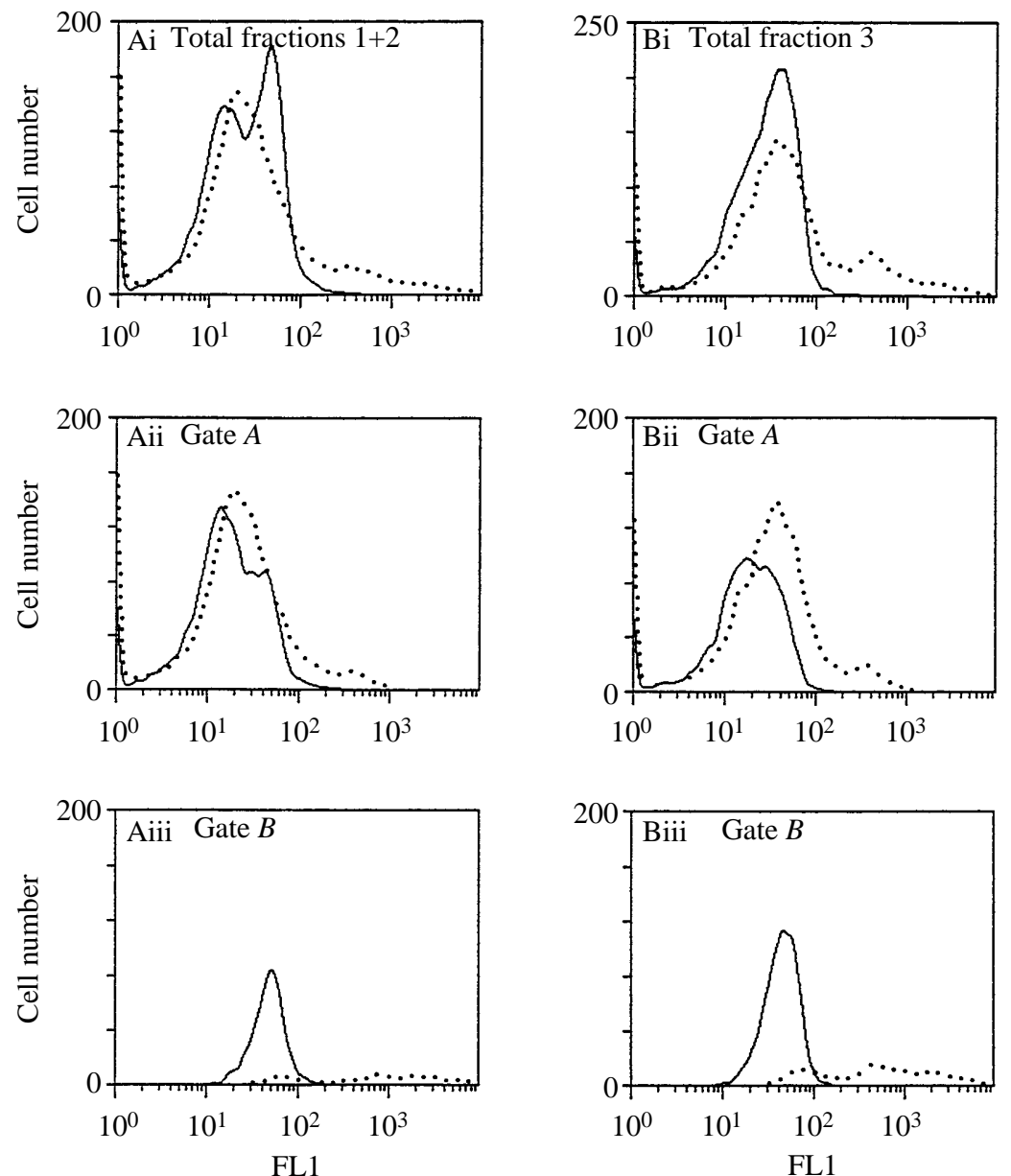

Fig. 6. Production of reactive oxygen intermediates in PMA-stimulated (dotted lines) and non-stimulated (solid lines) carp pronephros cells from fractions $1+2$ (Ai-iii) and 3 (Bi-iii). Cells were loaded with DHR123 for $60 \mathrm{~min}$ and subsequently incubated for $1 \mathrm{~h}$ with or without $0.1 \mu \mathrm{g} \mathrm{ml}^{-1}$ PMA. i, ii and iii show fluorescence (FL1) measurements in the total cell fraction and in gates $A$ and $B$, respectively (see Fig. 1). Fluorescence intensity was measured with a reduced voltage setting of the photomultiplier tube. Average non-stimulated and stimulated values were: for fraction $1+2,25$ and 53 in gate $A, 60$ and 1544 in gate $B$; for fraction 3, 52 and 69 in gate $A, 82$ and 1143 in gate $B$. 
After stimulation with PMA, the fluorescence of the cells within gate $B$ of both fractions increased considerably (Fig. 6Aiii,Biii). Increases in fluorescence of cells within gate $A$ were much smaller (Fig. 6Aii,Bii). Moreover, the relative cell numbers in gate $B$ decreased, parallel to an increase in gate $A$. The percentage of cells with highly elevated fluorescence (FL1 more than 200 units) after PMA stimulation was $11.0 \%$ in fraction 2 and $17.6 \%$ in fraction 3. Without PMA incubation, only $0.7 \%$ of the cells had values as high as this. Co-incubation with SOD resulted in a $25 \%$ increase of the fluorescence signal in all cases.

\section{Discussion}

From the results presented above it can be concluded that carp leucocytes can be separated, using density gradients and adherence, to enable analysis of $\mathrm{O}_{2}{ }^{*}$ and $\mathrm{H}_{2} \mathrm{O}_{2}$ for determination of respiratory burst activity in enriched cell fractions. With fluorescenceactivated cell sorting and subsequent EM analysis, different cell populations could be defined within these fractions which, moreover, could be separately analysed for respiratory burst activity at the single-cell level. These are useful tools for a study of the factors regulating macrophage and granulocyte activity.

Functional in vitro and in vivo characterization of fish macrophages and granulocytes is severely hampered by the absence of markers for the isolation and study of pure cell populations, and by the absence of well-characterised cell lines. Therefore, cell separation is generally based on differences in cell density. Flow cytometric analysis, and in some cases fluorescence-activated cell sorting (FACS), theoretically provides a very powerful tool but, unlike the situation in mammals, fish leucocytes do not separate into populations with distinct FSC/SSC profiles. This, combined with the absence of specific antibodies, limits the exploitation of flow cytometric techniques.

In this study, electron microscopic, light microscopic and flow cytometric analyses of different density fractions of pronephros cells showed that, for neutrophilic granulocytes, functional studies can be performed with the adherent cell population, which has a density range of $1.070-1.083 \mathrm{~g} \mathrm{~cm}^{-3}$. The purity of this fraction is estimated to be $85 \%$. Moreover, with FACS sorting it was possible to obtain from this fraction an essentially pure population of neutrophilic granulocytes. It was possible to study macrophage function by using enriched fractions, obtained by adherence of cells in the density ranges $1.020-1.060 \mathrm{~g} \mathrm{~cm}^{-3}$ (fraction 1) and $1.060-1.070 \mathrm{~g} \mathrm{~cm}^{-3}$ (fraction 2), which both contained approximately $60 \%$ macrophages. Neutrophilic granulocytes formed the main impurity. Flow cytometric analysis showed that macrophages have a scattered FSC/SSC profile, which demands careful interpretation of the results. This was anticipated, as light and electron microscopic analyses revealed that macrophages have an irregular shape and size, whereas neutrophilic granulocytes, although different in size, are predominantly globular.

Morphological analyses of the different cell fractions and analyses of phagocytosis are largely in line with the findings of Bayne (1986) and Temmink and Bayne (1987). Although the main density ranges could be determined for each cell type, all cell types investigated had a minor population with a broad density range. As the pronephros is a 
haematopoietic organ, one may predict that different subsets or several developmental stages of cells would be present. Electron microscopic analyses of distinct density fractions revealed the presence of macrophages and granulocytes of different size and granularity. However, phagocytosis was not clearly related to cell size, density or granularity.

Light and electron microscopic analyses of the phagocytic process in vitro indicate that, of the cells studied, macrophages are most efficient phagocytic cells. In contrast to the results of Temmink and Bayne (1987), we show that basophilic, eosinophilic and mixed-type granulocytes are also capable of in vitro phagocytosis. Moreover, opsonisation was an important stimulatory factor of phagocytosis by macrophages and neutrophilic granulocytes. Matsuyama et al. (1992) recently demonstrated for carp neutrophilic granulocytes that the opsonisation effect is induced by complement in both immune and non-immune sera. In the present experiments, non-immune serum was used and, because it has previously been demonstrated that pronephros macrophages and neutrophilic granulocytes, in contrast to gut macrophages, do not bind immunoglobulin (Rombout et al. 1991), it is suggested that complement is also the major opsonising factor for carp macrophages.

In mammals, the mechanism by which phagocytes kill microorganisms, although extensively studied, is not completely understood. The respiratory burst reaction is important because it, upon membrane stimulation, triggers the production of reactive oxygen intermediates (ROI), which have potent microbiocidal activity (Cross and Jones, 1991). Through activation of the membrane enzyme NAD(P)H oxidase, molecular oxygen is reduced into the superoxide anion $\left(\mathrm{O}_{2} \dot{*}\right)$ radical. Some of the $\mathrm{O}_{2}{ }^{*}$ generated is reduced to another microbiocidal molecule, $\mathrm{H}_{2} \mathrm{O}_{2}$. The latter reaction is partly catalysed by the enzyme superoxide dismutase (SOD). The phagocytes of several fish species show chemiluminescence, which is probably caused by $\mathrm{O}_{2}{ }^{*}$ (Bielek, 1981). Moreover, for an enriched population of trout macrophages, the generation of both $\mathrm{O}_{2}{ }^{-}$and $\mathrm{H}_{2} \mathrm{O}_{2}$ has been demonstrated (Chung and Secombes, 1987, 1988). Respiratory burst analysis in three defined density fractions with major macrophage and neutrophilic granulocyte populations now demonstrates that, in carp phagocytes as well, both $\mathrm{O}_{2}{ }^{-}$and $\mathrm{H}_{2} \mathrm{O}_{2}$ are formed after membrane stimulation with PMA or bacteria. Moreover, SOD induced a substantial decrease in NBT reduction together with an increase in Phenol Red oxidation, in line with the concept of a dismutase-catalysed reaction of $\mathrm{O}_{2} \dot{ }$ into $\mathrm{H}_{2} \mathrm{O}_{2}$. Positive reactions with intracellular NBT reduction, as well as the measurement of extracellular Phenol Red oxidation, imply that the ROI will not only be active within the phagosome, but also be released to the extracellular environment.

Our results show that fish pronephros cells can be effectively loaded with DHR123 in distinct populations of cells separated from heterogeneous fractions using flow cytometry. Therefore, analysis is no longer limited to the adherent cell population and may give insight into the percentage of all cells that contributes to the respiratory burst activity. From the substantial increase in fluorescence after SOD treatment, which is comparable to that found with the Phenol Red method, it is concluded that rhodamine is sensitive to intracellular $\mathrm{H}_{2} \mathrm{O}_{2}$. This is in line with findings reported for human monocytes (Emmendorfer et al. 1990). 
The results obtained for cells from fractions 2 and 3, with both methods of intracellular respiratory burst analysis, support the concept that the neutrophilic granulocytes of carp are the most active cell type in this respect. In view of the high number of these cells found in pronephros and peripheral blood (B. M. L. Verburg-van Kemenade, personal observations), it therefore seems likely that this cell type will contribute most to the microbiocidal activity. Flow-cytometric analysis reveals neutrophilic granulocytes within at least two distinguishable populations. The pure population of neutrophilic granulocytes at high FSC/SSC is readily activated by PMA. This is deduced from the finding that the basic DHR fluorescence was found in essentially one peak with a relatively high fluorescence signal. Upon activation by PMA, the peak shifts to the area of highest fluorescence. Cell populations with low FSC/SSC only contain a small percentage of cells with a relatively high fluorescence upon activation, above a peak of high basal fluorescence. Possibly neutrophilic granulocytes with low FSC/SSC represent a less active population. The reason for this phenomenon may be a high turnover of cells in this population, which might be reflected in the relatively large number of small granulocytes. Upon activation, a substantial fraction of the cells with high FSC/SSC showed a shift towards the lower FSC/SSC area, and this shift could be partly explained by the percentage of cells that become inactive after initial stimulation in vitro. Moreover, we cannot exclude the possibility that PMA treatment results in the occurrence of cells with unusual FSC/SSC characteristics. Cell viability was checked before and after incubation, and in vitro incubation of the cells is possible for several days without loss of activity (B. M. L. Verburg-van Kemenade, personal observation), so we conclude that these shifts are not related to cell death.

Although macrophages are abundant in fractions 1 and 2, it appears to be difficult to establish their relative contribution to the respiratory burst activity. Especially in fraction 2 , part of the activity measured is undoubtedly due to the population of neutrophils. In contrast to the results obtained for intracellular ROI, after activation the macrophage fraction showed the highest level of extracellular ROI, possibly indicative of a role in extracellular killing of microorganisms. The flow cytometric analysis suggested that the population of small macrophages with low FSC/SSC is relatively inactive, providing further, albeit indirect, evidence that they represent a population of developing macrophages. However, both the small macrophages and the small neutrophilic granulocytes were phagocytically active. In this respect, it is interesting to note that in comparison with PMA, bacteria were able to induce a much higher respiratory burst activity in all cell fractions. One explanation for this might be that other secondmessenger systems are involved in addition to protein kinase $\mathrm{C}$ activation.

Although lymphocytes are generally considered to have negligible respiratory burst activity, positive reactions have been reported (Leca et al. 1991). From our recordings we conclude that carp lymphocytes do not contribute substantially to the respiratory burst response.

We thank S. Hermsen, C. Kuil, A. Mensink, R. Merkelbach, L. Nagelkerke and V. Ruiz-van Haperen, who contributed to this research as part of their Masters degree research projects. Mrs E. Harmsen and Mrs A. Taverne-Thiele provided excellent 
technical assistance. Dr R.E. Stet is thanked for stimulating discussions. Critical reading of the manuscript by Drs R. E. Stet and G. Flik is appreciated.

\section{References}

BAYNe, C. J. (1986). Pronephric leucocytes of Cyprinus carpio: Isolation, separation and characterization. Vet. Immunol. Immunopathol. 12, 141-151.

BAYNe, C. J. AND LeVY, S. (1991). Modulation of oxidative burst in trout myeloid cells by adrenocorticotropic hormone and catecholamines - mechanisms of action. J. Leukocyte Biol. 50, $554-560$.

BIELEK, E. (1981). Developmental stages and localization of peroxidatic activity in the leucocytes of three teleost species (Cyprinus carpio L.; Tinca tinca L.; Salmo gairdneri Richardson). Cell Tissue Res. 220, 186-180.

BLALOCK, J. E. (1992). Production of peptide hormones and neurotransmitters by the immune system. In Neuroimmunoendocrinology, Chemical Immunology, vol. 52 (ed. J. Blalock), pp. 1-24. Basel: Karger.

Chung, S. And Secombes, C. J. (1987). Activation of rainbow trout macrophages. J. Fish Biol. 31, $51-56$.

Chung, S. And Secombes, C. J. (1988). Analysis of events occurring within teleost macrophages during the respiratory burst. Comp. Biochem. Physiol. 89B, 539-544.

CoHEn, N. AND Haynes, L. (1991). The phylogenetic conservation of cytokines. In Phylogenesis of Immune Functions (ed. G. Warr and N. Cohen), pp. 241-261. Boca Raton, FL: CRC Press.

Cross, A. R. And Jones, O. T. G. (1991). Enzymic mechanisms of superoxide production. Biochem. biophys. Acta. 1057, 281-298.

ElLIS, A. E. (1977). The leucocytes of fish: a review. J. Fish Biol. 11, 453-491.

Emmendorfer, A., Hecht, M., Lohmann-Matthes, M. AND RoESLER, J. (1990). A fast and easy method to determine the production of reactive oxygen intermediates by human and murine phagocytes using dihydrorhodamine 123. J. immunol. Meth. 131, 269-275.

HINE, P. M. (1992). The granulocytes of fish. Fish Shellfish Immunol. 2, 79-98.

Leca, G., Benichou, G., Bensussan, A., Mitenne, F., Galanaud, P. and Vasquez, A. (1991). Respiratory burst in human B lymphocytes. J. Immunol. 146, 3542-3549.

MacArthur, J. I. And Fletcher, T. C. (1985). Phagocytosis in fish. In Fish Immunology (ed. M. J. Manning and M. F. Tatner), pp. 29-46. London: Academic Press.

Matsuyama, H., Yano, T., Yamakawa, T. and NakaO, M. (1992). Opsonic effect of the third complement (C3) of carp (Cyprinus carpio) on phagocytosis by neutrophils. Fish Shellfish Immunol. 2, 69-78.

Olivier, G., EATON, C. A. AND CAMPBell, N. (1986). Interaction between Aeromonas salmonicida and peritoneal macrophages of brook trout (Salvenius fontinalis). Vet. Immunol. Immunopathol. 12, $223-234$.

PICK, E. AND KeISARI, Y. (1980). A simple colorimetric method for the measurement of hydrogen peroxide produced by cells in culture. J. immunol. Meth. 38, 161-170.

PICK, E. AND Mizel, D. (1981). Rapid microassays for the measurement of superoxide and hydrogen peroxide production by macrophages in culture using an automatic enzyme immunoassay reader. J. immunol. Meth. 46, 211-226.

Rombout, J. H. W. M., van Diepen, J. C. E., van Lisdonk, M. H. M., Taverne-Thiele, J. J. And Verburg-VAN KemenAde, B. M. L. (1991). Ig-binding capacity of carp macrophages. Dev. comp. Immunol. 15, S85.

Rook, G. A. W., Steele, J., Umar, S. and Dockrell, H. M. (1985). A simple method for the solubilisation of reduced NBT and its use as a colorimetric assay for activation of human macrophages by gamma-interferon. J. immunol. Meth. 82, 161-167.

Rothe, G., OSER, A. AND VALET, G. (1988). Dihydrorhodamine 123: a new flowcytometric indicator for respiratory burst activity in neutrophil granulocytes. Naturwissenschaften. 75, 354-355.

Rowley, A. F., Hunt, T. C., Page, M. And Mainwaring, G. (1988). Fish. In Vertebrate Blood Cells (ed. A. F. Rowley and N. A. Ratcliff), pp. 257-334. Cambridge: Cambridge University Press. 
Secombes, C. J. (1991). The phylogeny of cytokines. In The Cytokine Handbook (ed. A. W. Thomson), pp. 387-413. London: Academic Press.

Secombes, C. J., Chung, S. And Jeffries, A. H. (1988). Superoxide anion production by rainbow trout macrophages detected by the reduction of cytochrome C. Dev. comp. Immunol. 12, 201-206.

Temmink, J. H. M. AND BAYNe, C. J. (1987). Ultrastructural characterization of leucocytes in the pronephros of carp (Cyprinus carpio, L.). Dev. comp. Immunol. 11, 125-137.

Verburg-van Kemenade, B. M. L., Kuyl, C., Smith, R., Groeneveld, A. and Rombout, J. H. W. M. (1991). In vitro interleukin activities involved in carp macrophage-lymphocyte interaction. Dev. comp. Immunol. 15, S83. 